\title{
. \\ COOPERAÇÃO NO APL DE SANTA RITA DO SAPUCAÍ
}

ANA ROSA DE SOUSA

Mestra em Administração pelo Programa de Pós-Graduação em Administração da Universidade Federal de Lavras (Ufla). Coordenadora e professora do Departamento de Administração do Centro Universitário de Lavras (Unilavras). Rua Padre José Poggel, 506, Centenário, Lavras - MG - Brasil - CEP 37200-000

E-mail: anarosa@unilavras.edu.br

\section{MOZAR JOSÉ DE BRITO}

Doutor em Administração pela Faculdade de Administração e Economia da Universidade de São Paulo (USP).

Professor associado IV do Departamento de Administração e Economia da Universidade Federal de Lavras (Ufla).

DAE/Ufla, Campus Universitário, Lavras - MG - Brasil - CEP 37200-000

E-mail:mozarbrito@gmail.com

PAULO JOSÉ SILVA

Doutor em Administração pelo Departamento de Administração e Economia da Universidade Federal de Lavras (Ufla).

Professor do Departamento de Engenharia Civil do Centro Universitário de Formiga (Unifor). Avenida Doutor Arnaldo Sena, 328, Campus Universitário, Água Vermelha, Formiga - MG - Brasil - CEP 35570-000

E-mail: paulojoses@uol.com.br

\section{UAJARÁ PESSOA ARAÚJO}

Doutor em Engenharia de Produção pela Escola de Engenharia de São Carlos da Universidade de São Paulo (USP).

Professor adjunto do Departamento de Ciências Sociais Aplicadas do Centro Federal de Educação Tecnológica de Minas Gerais (Cefet-MG). Avenida Amazonas, 7.675, Campus II, Cefet-MG, Nova Gameleira, Belo Horizonte - MG - Brasil - CEP 30510-000

E-mail: vajara@dcsa.cefetmg.br

I Esta pesquisa foi financiada com recursos do Conselho Nacional de Desenvolvimento Científico e Tecnológico (CNPq).

Este artigo pode ser copiado, distribuído, exibido, transmitido ou adaptado desde que citados, de forma clara e explícita, o nome da revista, a edição, o ano e as páginas nas quais o artigo foi publicado originalmente, mas sem sugerir que a RAM endosse a reutilização do artigo. Esse termo de licenciamento deve ser explicitado para os casos de reutilização ou distribuição para terceiros. Não é permitido o uso para fins comerciais. 


\section{RESUMO}

Neste trabalho, apresentam-se os principais resultados de pesquisa na qual se investigaram os construtos explicativos das relações de cooperação entre as empresas integrantes do arranjo produtivo local (APL) localizado na cidade de Santa Rita do Sapucaí, em Minas Gerais. Para tanto, recuperaram-se alguns aspectos da gênese, do desenvolvimento e da configuração do referido arranjo. Posteriormente, foi elaborada uma proposta teórico-metodológica que serviu de referência para a produção de explicações sobre relações entre os construtos cooperação, confiança, benefícios, entre outros. Para testar e validar a referida proposta, aplicaram-se duas técnicas de análise multivariada: análise fatorial e regressão polinomial. As análises dos resultados da pesquisa evidenciaram a existência de correlações que indicam percepção positiva dos gestores em relação à governança promovida no âmbito do arranjo produtivo e aos benefícios advindos da cooperação. Estes últimos são vistos pelos gestores como geradores de algumas vantagens individuais e coletivas para as empresas participantes da pesquisa. Finalmente, os resultados desta pesquisa contrariam algumas formulações da proposta teórico-metodológica utilizada para explicar as relações de confiança construídas entre as empresas que atuam numa mesma base territorial. Indicam ainda que esse APL exemplificaria bem a importância de dois elementos institucionais: a governança (no caso, Sindicato das Indústrias de Aparelhos Elétricos, Eletrônicos e Similares do Vale da Eletrônica - Sindvel - e poder público local) e a interveniência de entidades educacionais que, além de assegurarem a qualificação da mão de obra, assumiram a tarefa de incubar empresas. Não parece inapropriado afirmar que o APL deve a sua criação e, mesmo, o seu desenvolvimento à atuação desses entes, conjuminada com a ação de pessoas visionárias, que ocuparam cargos diretivos nessas entidades. Como qualquer outra pesquisa, esta investigação sofreu com limitações. Entre outras, está o corte transversal dos dados: enquanto se admite a importância da dinâmica histórica, apresenta-se uma análise pontual. 


\section{PALAVRAS-CHAVE}

Cooperação. Confiança. Arranjos produtivos locais. Governança. Santa Rita do Sapucaí.

\section{INTRODUÇÃO}

Desde que Porter (I998) chamou a atenção para os clusters de vinho na Califórnia (Estados Unidos) e de artigos de moda de couro na Itália, os arranjos produtivos locais (APL) e os sistemas locais de inovação vêm gradativamente emergindo como solução interessante para alavancar resultados de pequenas e médias empresas.

Na presente pesquisa, lidou-se com cooperação em um APL. Em linha com Porter (I998), recepcionado por Lastres, Cassiolato e Marciel (2003), entende-se APL como uma aglomeração geográfica de empresas interconectadas que atuam em um determinado campo, suportadas por um conjunto de entidades compreendendo fornecedores de insumos e de máquinas, fabricantes de produtos complementares, distribuidores, provedores de infraestrutura, bem como escolas técnicas e centros tecnológicos, agências de fomento e associações comerciais e industriais que fornecem treinamento especializado, informação, pesquisa e suporte técnico. Uma vez que o APL de eletroeletrônica de Santa Rita de Sapucaí, em Minas Gerais, apresenta tais características, descritas com maiores detalhes na seção 3 deste trabalho, ele foi considerado como objeto do estudo apropriado à pesquisa, em consonância com Matos e Quelhas (2007, 2008), Botelho, Carrijo e Kamasaki (2007), Vilela, Perreira e Adriano (2008), Carvalho (2009), Tavares (20II), Lopes, Muÿlder e Judice (20II), Santos e Paula (20I2) e Martins e Souza (20I3), que também consideraram a aglomeração de empresas daquele município como APL.

Já a cooperação foi admitida como um processo social que se encontra enraizado no contexto histórico-social das redes organizacionais ou vinculado a ele, consistindo em uma prática vivenciada por organizações interessadas no desenvolvimento de interesses coletivos. Nesse sentido, considerou-se a cooperação como ação coletiva que permite ou induz a ação em rede e não como uma disposição psicológica coletiva (Pesämaa \& Hair, 2008).

Especificamente, pretendeu-se responder à seguinte questão de pesquisa: "Quais seriam os construtos teóricos que poderiam explicar as relações de cooperação estabelecidas entre as empresas do APL de Santa Rita do Sapucaí?".

Para tanto, buscou-se construir um modelo inicial derivado da literatura sobre APL e sobre cooperação baseado na teoria institucional e, mais especificamente, 
na teoria de redes. Em seguida, procurou-se evidenciar aspectos descritivos da formação e da estrutura social do arranjo objeto do estudo, aproximando a teoria das constatações empíricas. Daí, foi proposta uma escala de mensuração dos elementos explicativos das relações de cooperação estabelecidas entre as organizações pertencentes ao referido arranjo, para culminar em um segundo modelo, dito explicativo, das relações de cooperação.

Os dados empíricos iniciais foram coletados de documentos e de entrevistas que: I. permitiram explicitar o contexto histórico-social no qual os atores (basicamente, donos ou dirigentes de empresa) percebem as variáveis indutoras da cooperação e praticam a sua ação e 2. subsidiaram a elaboração de um questionário idealizado também a partir do modelo. Assim, gerou-se um banco de dados que foi refinado pela análise fatorial e, finalmente, submetido às análises de correlação e polinomial.

O modelo teórico ligava cooperação à confiança, à governança e aos benefícios percebidos pela atuação na rede. Ao final, constatou-se que o modelo teórico, com uma adaptação, sobreviveu, em parte, ao teste proposto, tal como descrito nas páginas finais do artigo que, antes, apresenta o referencial teórico que embasou o modelo teórico, seguido por uma breve descrição histórica e social do APL de Santa Rita. A descrição mais detalhada dos procedimentos metodológicos da pesquisa é encontrada na quarta seção, que precede a parte final, reservada para a apresentação e a discussão das análises empreendidas, bem como as considerações finais.

\section{FUNDAMENTAÇÃO}

O modelo teórico de partida da pesquisa derivou de considerações sobre os APL, com foco nas relações de cooperação e de confiança, e, ainda, nos antecedentes e nos benefícios da cooperação na rede. Nesta seção, apresenta-se uma breve síntese do que foi estudado.

\subsection{APL}

A expressão "redes organizacionais" tem sido empregada na tentativa de explicar alguns fenômenos que dão origem a novos formatos organizacionais que contemplam diversos tipos de relação entre as organizações. Como as espécies de redes são variadas, foi necessário criar uma tipologia, como a de Grandori e Soda (I995) que as classificaram em: I. redes burocráticas - como os consórcios de pesquisa e desenvolvimento (P\&D), as associações comerciais e industriais, os cartéis, as redes produtor-distribuidor, as relações de licenciamento e as 
franquias; 2. redes proprietárias - no caso, joint-ventures e as capital-ventures; e 3. redes sociais - incluindo distritos industriais, sistemas de beneficiamento por terceiros, subcontratação e redes de relacionamento. Nessa classificação, o APL apareceria como uma rede social, mas propõe-se que seria admissível admitir nuanças de burocracia intermediando as empresas, com seus contratos, e na atuação do sindicato que será apresentada ao longo do artigo.

As redes são investigadas em diversos aspectos, como inovação, recursos, confiança, oportunismo e legitimidade, o que permite o emprego das mais variadas óticas da ciência administrativa, como economia organizacional e industrial, evolucionismo histórico, teoria da negociação, teoria da dependência de recursos, institucionalismo, competências essenciais, psicologia social e outras (Araújo, 20II). Aqui se voltou para a cooperação em rede primordialmente social, sob a perspectiva do institucionalismo.

As redes podem ser vistas como uma resposta às necessidades de maior flexibilidade e de redefinição das fronteiras competitivas. Tais arranjos contribuem para a redução das incertezas do mercado e para o compartilhamento de informações. Além de gerar benefícios socioeconômicos, também potencializam a construção de relacionamentos sólidos entre organizações, fortalecendo a capacidade de investimentos, viabilizando ganhos de produtividade e possibilitando a obtenção de vantagem competitiva (Dyer \& Singh, I998). Particularmente, essas capacidades poderiam ser alcançadas por meio de aglomeração de empresas em um determinado território, com implicações significativas sobre os processos de cooperação e de competição, bem como sobre os benefícios advindos do ambiente institucional formado nesse tipo de aglomeração (Vasconcelos, Goldszmidt, \& Ferreira, 2005). Já se tem produzido um volume significativo de pesquisa sobre esses arranjos (Brusco, I990; Ciccone \& Cingano, 2003; Lastres \& Cassiolato, 2003; Marshall, I966; Parrilli, 2007; Porter, I998, I999; Serviço Brasileiro de Apoio às Micro e Pequenas Empresas, 2003), mas ainda seriam relevantes outros trabalhos que investigassem os fatores que facilitam a criação e o dinamismo dessas redes, mesmo porque elas têm um caráter histórico-geográfico próprio e incomunicável.

Há razoável consenso em adotar a caracterização de Porter (2000) de cluster para apontar as propriedades esperadas de um APL. Para Porter (1998, 2000), um cluster tem as seguintes características:

- Um grupo de empresas e instituições geograficamente próximas, incluindo, com frequência, fornecedores especializados de componentes, máquinas, serviços e infraestrutura, distribuidores, indústrias complementares, escolas técnicas, centros de pesquisa, associações industriais e comerciais, e agências públicas de apoio. 
- Empresas e instituições conectadas entre si por aspectos comuns ou complementares.

- Empresas e instituições voltadas para um campo econômico particular.

- Empresas e instituições que trocam entre si bens, serviços, informação e incentivos, e que compartilham vantagens, como aumento de produtividade, da ocorrência de inovações e de novos negócios, advindas de spillovers (extravasamentos, externalidades) entre suas entidades, bem como necessidades, oportunidades, obstáculos e restrições.

Grupos de empresas próximas geograficamente, com laços fracos e/ou de uma única indústria, não deveriam receber o status de APL, por tal definição. Mas ressalta-se que mesmo Porter (2000) admite que a delimitação apropriada do cluster pode variar, dependendo da localização, do segmento econômico e do nível de agregação.

A vantagem em identificar corretamente um cluster estaria em entender as ligações, competências, complementaridades e externalidades, o que favoreceria o empreendimento de ações coletivas, canalizaria a rivalidade, aumentaria a competitividade (pelo acesso à mão de obra, suprimentos especializados e informação, pela complementaridade de produtos e de marketing e pelo acesso aos bens e às instituições públicas, por exemplo), estimularia a inovação e apontaria um papel para o governo, que poderia agir e beneficiar simultaneamente várias empresas e uma região.

A proximidade geográfica, cultural e institucional confere às empresas do APL acesso diferenciado a melhores informações, relacionamentos mais próximos e maiores oportunidades de formação de novos negócios, o que é crucial para a competitividade baseada em conhecimento (Porter, I998), como na indústria de eletroeletrônica, e aumenta a competitividade de seus participantes. Trabalhos empíricos, como o de Baptista e Swann (I998), corroboram os de Porter (I998, 2000) e indicam que as empresas em APL são mais inovadoras devido aos efeitos do spillover de novos conhecimentos tecnológicos, que tenderiam a ser localizados geograficamente - ainda que, em alguns casos, como aqueles encontrados por Pouder e John (I996), em cluster de firmas concorrentes, de alto crescimento depois de usufruírem as vantagens da aglomeração, das forças institucionais e dos modelos mentais dos gerentes que criam um ambiente inovador, são mais suscetíveis às crises a partir do momento que as mesmas forças uniformizam a "macrocultura", podendo deprimir o movimento inovador.

Outro aspecto que merece atenção é como se daria a inserção competitiva do APL na cadeia de valor em escala global, principalmente de produtos tecnológicos (como eletroeletrônicos), e em cadeias coordenadas como "quase hierarquia", 
em um mercado assimétrico dominado por grandes compradores. Para Humphrey e Schmitz (2002), em tais estruturas, há maior facilidade para exportar, e as empresas do APL conseguem rápida ampliação das suas competências de processo (em termos de eficiência) e de desenvolvimento de produto para um padrão mais sofisticado. Contudo, são inibidas em utilizar suas competências para diversificar seus produtos (combiná-las de outras formas e criar outros produtos) e entrar em novos mercados, bem como encontram barreiras para buscar novos clientes, o que configura uma relação de subordinação e não de interdependência, até que o APL, de alguma forma, ultrapasse tais barreiras e um novo equilíbrio seja estabelecido.

Cassiolato e Szapiro (2003) chamam a atenção para os vínculos sólidos entre as entidades do APL - empresas, sindicatos, escolas, prefeitura -, voltados para a cooperação, a interação e o aprendizado. Um aspecto característico dos APL seriam tais laços das empresas com os agentes institucionais locais, que suprem as condições para a realização da produção social e a estabilidade da aglomeração (Amaral, 20II), bem como o suporte, inclusive financeiro, de agências e dos organismos públicos voltados para o desenvolvimento regional e ao apoio a pequenas empresas, frequentes nessas aglomerações.

Se os laços são essenciais e as ligações no APL são desenvolvidas ao longo do tempo, então, o entendimento de um APL requer a análise de sua historiografia conectada ao condicionante geográfico, associando as trajetórias históricas de construção de identidades e de formação de vínculos territoriais, a partir de uma base social, cultural, política e econômica comum. Assim, ambientes favoráveis à interação, cooperação e confiança entre os atores permitem o desenvolvimento dos APL e daí decorreria a vantagem do arranjo: sua capacidade de criar e manter vantagem competitiva para as organizações inseridas no APL, ante aquelas que estão dispersas no território (Lastres et al., 2003).

Sintetizando com o auxílio de Lastres et al. (2003), seriam características dos APL: a proximidade geográfica, a especialização setorial, a participação de pequenas e médias empresas, a colaboração intensiva, o processo competitivo baseado em inovação, a confiança como fator social e cultural, o apoio de organizações para serviços comuns e o apoio financeiro e de capital de agências locais e regionais.

O APL de Santa Rita vem sido investigado há algum tempo, entre outros, por Matos e Quelhas (2007, 2008), Santos e Paula (20I2), Martins e Souza (2013) e Prado e Costa (2013) - mas ainda não se esgotaram todas as possibilidades para o entendimento das relações de cooperação na rede, como empreendido nesta pesquisa, que partiu de algumas contribuições teóricas sobre o fenômeno. 


\subsection{RELAÇÕES DE COOPERAÇÃO E CONFIANÇA NAS REDES ORGANIZACIONAIS}

A cooperação tem sido apontada como um construto central para a compreensão das relações entre empresas (Eriksson \& Pesämaa, 2007; Pesämaa \& Hair, 2007, 2008). Mas o termo é polissêmico, visto que a pesquisa sobre a natureza e os pressupostos que orientam a cooperação tem sido marcada pela pluralidade ontológica e epistemológica, não se obrigando ao limite de um único conceito universal.

Enfrentando a dificuldade de sistematizar e construir consensos teóricos sobre cooperação e as suas distintas formas de manifestação nos mais variados arranjos organizacionais cooperativos, observa-se que a pesquisa em administração tem contribuído para a produção de novos conhecimentos sobre a cooperação interorganizacional, como em Balestrin e Vargas (2004), Williams (2005), Bercovitz, Jap e Nickerson (2006), Medlin (2006), Edelenbos e Klijn (2007), Hanna e Walsh (2008) e Verschoore e Balestrin (2008).

Considera-se que a formação das redes organizacionais tem por princípio institucionalizar a ação coletiva organizada. Tais redes reuniriam algumas especificidades estruturais e relacionais que permitiriam a obtenção de ganhos a partir da construção de relações de cooperação orientada para a competição (Baiardi, 2008). Para Baiardi (2008, p. 49), "a propensão a cooperar no âmbito empresarial sugere que a organização, sem renunciar à competição no mercado, entenda que a cooperação pode levar todo o tecido produtivo a se tornar mais competitivo".

Reitera-se que a cooperação pode ser abordada como um processo social, cujas raízes estão atreladas ao contexto sócio-histórico em que se encontram inseridas, incluindo aquele inerente às redes organizacionais. Nesse caso, a cooperação seria concebida como uma prática vivenciada por organizações interessadas no desenvolvimento de interesses coletivos. Ao mesmo tempo, é reconhecido que as experiências e as competências das pessoas que agem em nome das organizações são fundamentais para a construção de consensos e do comprometimento com os objetivos da rede (Pesämaa \& Hair, 2008).

De tal forma, a cooperação interorganizacional pressuporia a convergência de interesses visando à concretização de ações que beneficiam a coletividade de organizações. Destaca-se que uma rede organizacional tem dupla vocação: social e econômica. Por um lado, ela deve contribuir para a obtenção de resultados econômicos, o que pressupõe a busca da eficácia e da eficiência; por outro, ela cumpre uma função social e agrega também crenças, ideologias e valores, como ajuda mútua, solidariedade, democracia e participação (Verschoore \& Balestrin, 2008). 
Para Verschoore e Balestrin (2008), a cooperação permite a constituição de relações estruturadas (social, cultural e economicamente) em rede com o propósito de atender aos objetivos individuais e coletivos dos seus participantes. Contudo, a obtenção e a manutenção desses benefícios derivados da cooperação dependeriam, por exemplo, da cultura local e da existência de parceiros de negócios comprometidos e com objetivos semelhantes (Hanna \& Walsh, 2008).

Lundin (2007) relaciona cooperação interorganizacional à confiança, tratando a última como um antecedente da primeira: a cooperação dependeria da existência da confiança mútua, bem como da congruência entre os objetivos. A confiança contribuiria para a criação e manutenção da interação e da ordem social (Inkpen \& Curral, 2004), especialmente nas situações desconhecidas e de consequências imprevisíveis, em condições de incerteza relativa às interações sociais em que prevalece a dialética do controle informal (Sydow \& Windeler, 2003). Por sua vez, a desconfiança impactaria de forma negativa a cooperação, reduzindo a capacidade de os gestores assumirem riscos e deprimindo a propensão deles ao compartilhamento de informações e conhecimentos (McEvily, Perrone, \& Zaheer, 2003; Bijlsma-Frankema, 2004).

A confiança teria três gêneses diferentes: calculativa, cognitiva e normativa. De acordo com Lane (I998, p. 4), confiança calculativa "envolve expectativa sobre o outro, com base no custo-benefício de certos cursos de ação do confiador ou do confiante". Nesse caso, a confiança seria sustentada pela racionalidade no sentido utilitarista e maximizador. Já a confiança cognitiva ou baseada no conhecimento (knowledge-based trust), como foi denominada por Lewicki e Bunker (1996), seria fundamentada na previsibilidade do outro, ou seja, no fato de conhecer e compreender o outro. Quanto à confiança do tipo normativo, entende-se como aquela dependente do compartilhamento de valores comuns entre os parceiros, considerando, inclusive, normas de obrigação que podem ser desenvolvidas, caso a relação exista há algum tempo (Lane, I998). Para Lewicki e Bunker (I996), esse tipo de confiança seria decorrente do fato de as partes compreenderem o desejo inerente a cada uma delas e apreciarem tais desejos. Assim, existiria uma boa chance de laços de amizade se desenvolverem ao longo do tempo, o que levaria uma parte a sentir e pensar como a outra.

Quando tomadas em conjunto, as indicações de Lewicki e Bunker (1996), Lane (I998), McEvily et al. (2003), Bijlsma-Frankema (2004), Lundin (2007) e Verschoore e Balestrin (2008) parecem indicar que haveria uma relação positiva entre a confiança existente entre os agentes de um arranjo e a propensão a cooperar desses sujeitos para a consecução de seus objetivos empresarias individuais e coletivos e/ou para aceitação e legitimação social de suas ações. Essa relação foi incorporada no meio do modelo teórico da subseção 4.I, como hipótese H2. As hipóteses $\mathrm{H}_{1}$ e $\mathrm{H}_{3}$ foram derivadas como exposto a seguir. 


\subsection{ANTECEDENTES E BENEFíCIOS DA COOPERAÇÃO EM REDE}

Para Verschoore e Balestrin (2008 p. I046), "os fatores relevantes para o estabelecimento de redes de cooperação se relacionam aos ganhos de competitividade obtidos pelas empresas associadas" a uma rede. As empresas cooperariam e ganhariam com isso; seriam mais competitivas e gozariam da redução das incertezas e dos riscos inerentes aos negócios (Williams, 2005); aproveitariam do acesso a soluções, da escala e do poder de mercado da rede; lucrariam com o maior acesso às informações e ao aprendizado, tendo maiores chances de sucesso em seu processo de inovação ao aglutinarem competências e outros recursos, múltiplos e acumulativos (Stallivieri, Guimarães, \& Souza, 2008; Verschoore \& Balestrin, 2008).

Os benefícios, reais ou meramente percebidos, advindos das ações cooperadas serviram de reforço à construção de novos esforços cooperativos, em um encadeamento positivo, tanto quando persistam os cálculos dessa ordem feitos pelos empreendedores, desde que o oportunismo (apropriação dos recursos da rede não referendada socialmente) seja contido. A relação positiva entre benefícios e a cooperação é perquirida no trabalho sob a denominação de hipótese $\mathrm{H}_{3}$.

Contudo, a construção de uma relação de interdependência entre a cooperação e os benefícios da ação em rede não pode ser descrita ou operacionalizada tão facilmente, pois ela seria entremeada com alguns fatores intervenientes. Entre esses fatores, destacam-se os padrões culturais compartilhados entre as organizações, a convergência de interesses, as especificidades territoriais e a estrutura de governança.

Para esta pesquisa, a governança foi definida como o processo de coordenação do conjunto de atividades de interesse coletivo desenvolvidas no âmbito de uma rede organizacional, em suas várias esferas de ação estratégica (Schmitter \& Streeck, I985). Seria um processo de regulação das diferentes dimensões (política e estratégica) da ação coletiva, visando à construção de acordos que viabilizem os interesses das organizações constitutivas da rede. Daí, a governança em redes implicaria a elaboração e implementação de ações direcionadas ao coletivo, o que pressupõe a inclusão de diversas organizações em um processo de coordenação e gestão que seja capaz de fortalecer as relações de confiança e cooperação.

Suzigan, Garcia e Furtado (2007) defendem que a existência de uma estrutura de governança dependeria: I. da distribuição espacial das organizações e das formas de divisão do trabalho entre elas; 2 . da existência de atividades econômica e de base tecnológica que possibilitem a cooperação; 3. da lógica coletiva de organização da produção; 4. de mecanismos coletivos de inserção mercadológica; 5. da presença de instituições locais que tenham interação com o setor produtivo; e 6 . do contexto sociocultural e político local que estimule a confiança e a cooperação, tal como discorrido até aqui. 
Para Humphrey e Schmitz (2002), a governança pode ser assumida por um agente privado local (associações de classe, agências locais privadas de desenvolvimento ou por sindicatos empresariais, que atuariam como agentes catalisadores da atuação em redes entre as organizações de uma mesma base territorial), por um agente público (na forma de agências de desenvolvimento local, programas de incentivos fiscais, incubadoras de empresas e entes encarregados da manutenção de uma estrutura de serviços públicos, como a qualificação da força de trabalho) ou por organizações líderes (responsáveis pela coordenação vertical das interações e das ações coletivas articuladas entre o conjunto das organizações constitutivas da rede). É evidente que mais de um tipo de governança pode se fazer presente em um APL. Desse modo, seria adequado ter uma definição clara dos papéis de cada agente no processo de governança coletiva, preservando as identidades e as vocações de cada agente quando, ao mesmo tempo, as suas competências e recursos seriam empregados de forma complementar. Exemplo da governança coletiva pode se encontrado em Baiardi e Laniado (2000, p. 49):

[...] no ambiente de redes ou entorno empresarial com definição no território, associações industriais ali localizadas prestam assistência administrativa e, até mesmo, financeira, enquanto os governos locais propiciam a infraestrutura e os serviços sociais indispensáveis, como treinamento profissional, informação sobre mercados de exportação e tendência mundial, etc.

Destaca-se que a governança estará sempre inserida em um dado contexto sociocultural e político local multifacetado (Suzigan et al., 2007). Assim, ela seria, em parte, decorrente da história das relações entre os diferentes atores da rede organizacional. A história das interações e suas especificidades poderiam ou deveriam ser vistas como construto antecedente da cooperação, reconhecendo que a cooperação pode ser ampliada à medida que a história das relações entre as organizações for, ao longo do tempo, construída - enquanto, concomitantemente, o fortalecimento dos laços de cooperação e confiança contribuiria para a perpetuação da história do relacionamento entre as organizações (Gulati \& Sytch, 2008).

Por fim, é necessário salientar que, além da confiança, outros fatores interferem na cooperação e, portanto, na aplicação da governança nas redes. Para Williams (2005), I. a formalização das relações poderá, em determinadas circunstâncias, impactar de forma negativa a cooperação - as definições formais de direitos e obrigações podem se revelar contrárias ou substitutivas da confiança e da cooperação entre as organizações; 2. a frequência e a densidade dos contatos entre as organizações podem ampliar a cooperação e a confiança entre elas; 3 . a centralização da rede, o que implica a existência de uma periferia mais 
descompromissada, reduziria a propensão à cooperação do conjunto; e 4. a permanência ou a estabilidade que terá impacto positivo na cooperação.

Outro fundamento interessante para a leitura dos APL remete à economia dos custos de transação (Coase, I937; Williamson, I996), que trabalha com conceitos como oportunismo, reputação, especificidade de ativos, frequência e incerteza das transações. Por essa ótica, as relações cooperadas interfirmas sofreriam com a propensão ao oportunismo (os agentes buscariam o seu autointeresse utilizando informações privilegiadas, rompendo contratos e ferindo códigos de ética) e são favorecidas pela frequência das transações - transações repetitivas inibem o oportunismo ao aumentarem o custo de se perder a reputação (o indivíduo não rompe o contrato, mesmo informal, quando avalia que, se o fizer, o custo do rompimento irá superar os benefícios, pelo prejuízo em sua reputação).

A partir de todos esses trabalhos citados previamente, admitiu-se, como ponto de partida, haver uma relação positiva entre a percepção da atuação da governança da rede e a propensão a cooperar, representada pela linha Hi no modelo teórico da subseção 4.I.

Todo este conjunto - cooperação, confiança, governança (em especial, poder local e agência privada) e benefícios da ação cooperada - demandou espaço nesta pesquisa, em um esforço mediado pelos procedimentos descritos na seção 4, precedida pela caracterização do campo escolhido para a pesquisa, a seguir.

\section{CONTEXTO SóCIO-HISTÓRICO DO APL}

A Escola Técnica de Eletrônica (ETE) "Francisco Moreira da Costa" foi criada em Santa Rita do Sapucaí em I959. Ela precedeu à criação de outras entidades de ensino, como o Instituto Nacional de Telecomunicações de Santa Rita do Sapucaí (Inatel), em I965, e a Faculdade de Administração e Informática (FAI), fundada em I97I. Tais escolas desenvolveram papel significativo no desenvolvimento da cidade, acelerado no final da década de i970, respondendo, em parte, pela instalação de empresas de tecnologia na região suplementada pela atuação de duas iniciativas: a Incubadora de Empresas e Projetos do Inatel em I985 e o Programa Municipal de Incubação Avançada de Empresas de Base Tecnológica (Prointec). A incubadora do Inatel tem projeção nacional, com uma escala que pode ser estimada pelos seus recursos, sabendo-se que ela dispôs, em 2009, de nove milhões de reais (oriundos da Financiadora de Estudos e Projetos - Finep) para apoiar até 75 empresas nascentes com produtos inovadores. Essa incubadora já tinha graduado, no momento da pesquisa, 43 empresas, 33 das quais em Santa Rita. O Prointec conta com uma incubadora de empresas (IME) para empreendimentos nascentes e inovadores e com o condomínio de empresas 
(CME) para companhias de maior porte (Matos \& Quelhas, 2007, 2008; Santos \& Paula, 20I2; Martins \& Souza, 20I3).

Concomitantemente com o desenvolvimento institucional da cidade, foram sendo criadas empresas com base tecnológica, já na década de I970. À medida que novas empresas iam se instalando, foi sendo concebida, com a liderança do poder público local e a participação dos empresários, a ideia de caracterizar o cluster emergente e a região como "Vale da Eletrônica", em uma iniciativa de marketing regional (Matos \& Quelhas, 2007, 2008).

Por meio de esforços conjuntos dos entes empresariais, educacionais e públicos, passaram a ocorrer feiras industriais e feiras tecnológicas nas escolas locais. Nesse ínterim, a prefeitura criou um curso noturno de montagem de circuitos eletroeletrônicos para treinar mão de obra para as empresas. Além disso, começaram a ser constituídos programas acadêmicos e não acadêmicos de apoio às empresas iniciantes, de maneira que o Vale da Eletrônica foi gradativamente apresentando resultados. Em I988, surgiram os primeiros efeitos econômicos: aumento da arrecadação municipal, elevação do padrão salarial da cidade, aumento no nível de emprego, entre outros (Matos \& Quelhas, 2007, 2008; Santos \& Paula, 20I2; Martins \& Souza, 20I3).

De acordo com a Federação das Indústrias do Estado de Minas Gerais Fiemg (2007), o APL contaria com mais de uma centena de firmas, constituindo um polo tecnológico que oferece quase dez mil empregos, produz e comercializa cerca de I2 mil produtos diferentes: telecomunicações (quase $22 \%$ das empresas), eletroeletrônica (mais de I8\%), segurança (mais de I2\%) e tecnologias de informação e automação (Iı\% cada), incluindo softwares, hardwares, centrais de alarmes, sensores, câmeras de vídeo, equipamentos para promoção agrícola e outros.

O polo, acrescido das demais entidades locais, deteria as características apresentadas para ser qualificado como APL e é reconhecido como tal, inclusive por organismos públicos, como o governo estadual. Tipicamente, é composto por empresas de capital nacional e de pequeno porte (Fiemg, 2004). Por atuar no ramo de produtos com base tecnológica, o APL de Santa Rita se destaca pela contribuição ativa dos seguintes agentes de ensino: Inatel, FAI, Escola Técnica de Eletrônica (ETE) "Francisco Moreira da Costa" e Serviço Nacional de Aprendizagem Industrial (Senai), provedores de capacitação tecnológica e pesquisa, em relação estreita com as empresas (Fiemg, 2004, 2007), com a interveniência substantiva do Sindicato das Indústrias de Aparelhos Elétricos, Eletrônicos e Similares do Vale da Eletrônica (Sindvel) e da prefeitura, articulando organismos externos de apoio e assistência a ações de capacitação, pesquisa tecnológica e inovações - como a Finep, a Fundação de Amparo à Pesquisa do Estado de Minas Gerais (Fapemig), o Banco de Desenvolvimento do Estado de Minas Gerais (BDMG), o Instituto Euvaldo Lodi (IEL) e o Conselho Nacional de Desenvolvimento Científico e Tecnológico (Prado \& Costa, 20I3). 
Dos dados da pesquisa que congregaram um subconjunto de 82 empresas entre aquelas associadas ao Sindvel, 53 são microempresas (de um a 20 funcionários), 20 pequenas empresas (de 2I a roo funcionários), oito empresas de médio porte (de Ior a 500 funcionários) e apenas uma é de grande porte (acima de 500 funcionários). Do subconjunto, 30\% afirmaram ter faturamento médio anual menor que R\$ Ioo mil; $33 \%$ na faixa de R\$ Ioo mil a R\$ 500 mil; I0\% de $\mathrm{R} \$ 50$ I mil a $\mathrm{R}$ I milhão; $15 \%$ de $\mathrm{R}$ I, O०I milhão a $\mathrm{R} \$ 5$ milhões e I2\% acima de $\mathrm{R} \$ 5$ milhões. A maioria dessas companhias (66\%) trabalha com produção própria, mas $51 \%$ delas terceirizam alguma parte do processo de produção, sendo "desenvolvimento" e "compra" as principais formas de terceirização. Entre aquelas que terceirizam, metade o faz, principalmente, com outras empresas do próprio APL. Uma minoria procura parceiros fora do Estado e menos ainda (seis empresas) trabalha usando firmas de outros países. Por fim, quase metade $(46 \%)$ das organizações da amostra afirmou atuar em conjunto, em feiras ou stands compartilhados e participando de missões internacionais.

Basicamente, o Vale da Eletrônica reúne todos os ingredientes preditos/ prescritos pela literatura de APL, como componente geográfico, componente histórico-social (sedimentando as relações), exploração de um setor econômico, multiplicidade de firmas concorrentes e complementares inter-relacionadas e em destaque, base educacional e elementos de coordenação, como confiança, atuação do poder local (prefeitura) e do sindicato das empresas (Sindvel).

\section{MÉTODO dE PESQUISA E RESULTADOS PRELIMINARES}

\section{CONCEPÇÃO DA PESQUISA E MODELO TEÓRICO}

Esta investigação pode ser enquadrada como uma pesquisa descritiva de natureza quantitativa (Marconi \& Lakatos, 2003), próxima ao método hipotético-dedutivo, que parte de um conjunto de hipóteses para submetê-la a um teste de validade, buscando a sua refutação, de acordo com Popper (I994). Entretanto, o teste de hipótese aqui foi proposto como meio, ou melhor, um roteiro e não como um fim em si mesmo. A ênfase está na compreensão do fenômeno em estudo - a cooperação interfirmas. Cabe ainda ressaltar que, mesmo utilizando métodos quantitativos mais próximos à epistemologia objetivista, não se perdeu de vista que as informações coletadas dos sujeitos são relativas à percepção de tais indivíduos sobre os fatos questionados.

As considerações teóricas motivaram a concepção do modelo, relacionando os construtos (conceito teórico não observável diretamente) “cooperação”, 
"confiança", "benefícios" e "governança”. O modelo e as relações hipotéticas de interesse (Hı, $\mathrm{H}_{2}$ e $\mathrm{H}_{3}$ ) podem ser vistos na Figura I.

\section{FIGURA I}

MODELO INICIAL INDICANDO AS RELAÇÕES HIPOTETTICAS

DE INTERESSE, CORRELACIONANDO TRES CONSTRUTOS -

GOVERNANÇA, CONFIANÇA E BENEFÍCIOS - COM

O CONSTRUTO COOPERAÇÃO

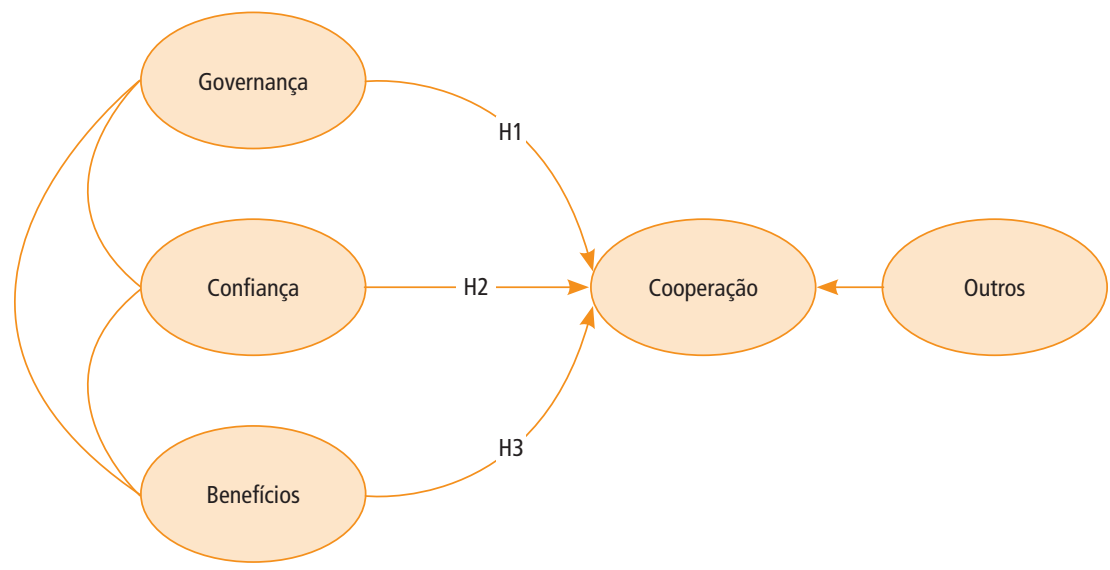

A variável “Outros” representa a parcela da variação da "Cooperação" não explicada pelos outros construtos.

Fonte: Elaborada pelos autores.

\subsection{COLETA DE DADOS}

De posse do modelo, foi elaborado um extenso questionário, com duas partes. A primeira com questões demográficas e a segunda constituída por 52 afirmativas. As assertivas originaram-se da fundamentação, em particular dos autores citados nas subseções 2.2 e 2.3, acrescida de entrevistas não estruturadas com representantes de empresas do APL - entre elas, o Sindvel -, de documentos públicos disponíveis, incluindo os Diagnósticos do Arranjo Produtivo da Indústria do Vale da Eletrônica dos anos de 2004 e 2007 e os acervos relativos à história do município de Santa Rita do Sapucaí e de seu APL.

Os respondentes foram solicitados a apontar seu grau de concordância em relação a cada afirmação, em uma escala do tipo Likert de 5 pontos (de concordo totalmente a discordo totalmente, portanto com ponto neutro). A opção por essa escala levou em consideração a natureza da variável a ser medida, a habilidade 
dos respondentes de fazer julgamentos e o tipo de análise a ser desenvolvida, em acordo com Oliveira (200Ia). Foi realizado um pré-teste com cinco elementos da população-alvo com a presença de um dos pesquisadores, com o objetivo de encontrar os pontos que pudessem gerar dificuldades de compreensão. Isso levou à adequação da redação de cinco itens do questionário. Apesar de a escala Likert ser uma escala ordinal, ela conduziu a dados que foram tratados como advindos de escala intervalar, prática usual em pesquisas tanto em marketing quanto em psicologia (Churchill, I994), mas que deve sofrer essa ressalva.

O universo da pesquisa foi constituído das II5 empresas, então filiadas ao Sindvel, consideradas como o cerne "produtivo" do APL. Todas elas, na figura de seus dirigentes (proprietários ou gerentes), foram contatadas em setembro de 2008. Retornaram 85 questionários, dos quais três foram descartados devido à falta de preenchimento da maioria das questões. Obteve-se, assim, uma amostra não probabilística de $82 / \mathrm{II} 5=7 \mathrm{I} \%$ (= número de questionários válidos sobre o universo considerado). Mesmo com tal proporção, seria inadequado fazer qualquer extrapolação de características da amostra para a população, pois, para tanto, se requer que a amostra seja aleatória e, assim, seja permitida a inferência estatística (Hair, Babin, Money, \& Samouel, 2005; Maroco, 2007), principalmente por não se poder assegurar a ausência de vieses relacionados a "não resposta" (Oliveira, 200Ib). Daí, todas as análises apresentadas doravante reportam exclusivamente à amostra (nomeada AAPL).

O desenho da pesquisa resultou em uma proporção afirmações/respondentes baixa, inferior a 2, portanto distante da recomendação de 5 a Io feita por Hair et al. (2005), por considerar a oportunidade como única e que deveria ser aproveitada da forma mais abrangente possível, confiando-se à análise fatorial a tarefa de reduzir as variáveis.

\section{TRATAMENTO INICIAL DOS DADOS VIA ANÁLISE FATORIAL}

Tal como recomendado em Hair et al. (2005) e Malhotra (200I), a análise fatorial foi empregada para: reduzir o conjunto de variáveis, facilitar a sumarização dos dados e prepará-los para a operação posterior - no caso, a regressão polinomial.

O nível de adequação da matriz de dados foi avaliado por meio da medida Kaiser-Meyer-Olkin (KMO). Computaram-se e estudaram-se também o nível de significância do teste de esfericidade de Bartlett, a matriz de anti-imagem (medida de adequacidade amostral), as comunalidades, os autovalores (eingenvalues) e, por fim, a confiabilidade de coerência interna (alfa de Cronbach). O método de extração de componentes principais, a rotação Varimax e a normalização de Kaiser foram as opções empregadas na análise fatorial. Das alternativas oferecidas por 
Malhotra (200I) para determinar o número de fatores, optou-se a priori por fazê-lo com base ao gráfico de declive (autovalores x número de fatores), identificando o ponto quando o declive toma a forma de uma "rampa mais suave". O pacote estatístico SPSS respondeu pelos cálculos, que se prestaram como base para discutir a validade da escala empregada para caracterizar os construtos empregados no modelo.

As variáveis (questões submetidas aos respondentes) que acabaram por ser incluídas nos construtos providos pela análise fatorial foram:

- VI: As relações de cooperação existentes entre as empresas têm contribuído para a ampliação da vantagem competitiva em relação aos concorrentes locais.

- V2: A cooperação entre empresas traz benefícios mútuos que dificilmente seriam alcançados sem a referida relação.

- V3: A contratação conjunta de serviços de consultorias especializadas tem sido considerada por nossa empresa como uma fonte de inovação relevante.

- $\quad V_{4}$ : O conhecimento transferido por outras empresas tem contribuído de forma significativa para que nossa empresa obtenha vantagens competitivas no mercado.

- V5: Posso confiar nas empresas com quais mantemos relações porque elas são transparentes e verdadeiras em seus propósitos.

- V6: Confio nas empresas com as quais me relaciono, porque conheço pessoalmente os seus dirigentes.

- V7: Posso confiar no comportamento ético e moral das empresas com as quais mantenho relacionamentos.

- V8: O Sindvel tem atuado de forma eficiente na coordenação das relações das empresas do arranjo produtivo de Santa Rita do Sapucaí.

- V9: O Sindvel tem um papel relevante na construção de uma visão coletiva que favorece o desempenho e crescimento do conjunto das empresas do Vale da Eletrônica.

- Vio: As empresas de Santa Rita com as quais mantenho relações estão comprometidas com o compartilhamento de recursos tecnológicos, conhecimentos e informações de mercado.

- Vir: As relações estabelecidas entre as empresas de Santa Rita do Sapucaí têm permitido a troca de informações sobre preços praticados por nossos parceiros.

- Vi2: As relações estabelecidas pela empresa por mim dirigida com outras empresas de Santa Rita do Sapucaí ampliaram os nossos canais de distribuição.

- Viz: As relações estabelecidas entre as empresas de Santa Rita do Sapucaí têm permitido a troca de informações sobre preços praticados por nossos concorrentes. 
- VI4: As informações sobre o mercado são trocadas com facilidade entre as empresas de Santa Rita do Sapucaí.

- Vi5: As relações estabelecidas com outras empresas têm permitido inovações incrementais (melhorias) em nossos produtos e processos tecnológicos.

- Vi6: O poder público de Santa Rita do Sapucaí tem formulado e implementado políticas públicas que favorecem o desenvolvimento empresarial.

- VI7: O poder público local tem concedido incentivos fiscais que favorecem a sobrevivência da nossa empresa.

- Vi8: O poder público local tem criado um ambiente institucional que favorece a inovação de produtos e processos tecnológicos.

A Tabela I apresenta a medida de adequacidade amostral (MSA) e comunalidade encontrada para as variáveis que, em conjunto, reportaram $\mathrm{KMO}=0,66_{3}$, significância < 0,00I\% e variância explicada de 50,45\%.

\section{TABELA I}

\section{MSA E COMUNALIDADE}

\begin{tabular}{ccc}
\hline VARIÁVEL & MSA & COMUNALIDADE \\
\hline V1 & 0,526 & 0,646 \\
\hline V2 & 0,806 & 0,743 \\
\hline V3 & 0,675 & 0,615 \\
\hline V4 & 0,711 & 0,701 \\
\hline V5 & 0,698 & 0,725 \\
\hline V6 & 0,624 & 0,624 \\
\hline V7 & 0,582 & 0,797 \\
\hline V8 & 0,732 & 0,663 \\
\hline V9 & 0,704 & 0,790 \\
\hline
\end{tabular}

\begin{tabular}{ccc}
\hline VARIÁVEL & MSA & COMUNALIDADE \\
\hline V10 & 0,785 & 0,642 \\
\hline V11 & 0,638 & 0,734 \\
\hline V12 & 0,783 & 0,735 \\
\hline V13 & 0,637 & 0,670 \\
\hline V14 & 0,810 & 0,726 \\
\hline V15 & 0,800 & 0,674 \\
\hline V16 & 0,423 & 0,797 \\
\hline V17 & 0,412 & 0,794 \\
\hline V18 & 0,425 & 0,747 \\
\hline
\end{tabular}

Nota: MSA = Medida de Adequação Amostral.

Fonte: Elaborada pelos autores.

A adequação da amostra à análise fatorial foi satisfatória com base nas comunalidades superiores a o,60, de acordo com as recomendações de Guadagnoli e Velicer (I988) e de MacCallun, Widaman, Zhang e Hong (I999). 
A análise fatorial apontou para uma escala com cinco fatores (denominados, via análise semântica, de "cooperação", "confiança”, "governança em rede", "benefícios da ação em rede" e "poder local"), derivados das variáveis originais, com as respectivas cargas fatoriais e o Coeficiente Alfa de Cronbach $(\alpha)$ apresentados na Tabela 2.

\section{TABELA 2}

MATRIZ FATORIAL

\begin{tabular}{|c|c|c|c|}
\hline CONSTRUTO & $\alpha$ & VARIÁVEL & CARGAS FATORIAIS \\
\hline \multirow{4}{*}{ Cooperação } & \multirow{4}{*}{0,63} & V1 & 0,681 \\
\hline & & V2 & 0,818 \\
\hline & & V3 & 0,616 \\
\hline & & V4 & 0,681 \\
\hline \multirow{3}{*}{ Confiança } & \multirow{3}{*}{0,77} & V5 & 0,897 \\
\hline & & V6 & 0,724 \\
\hline & & V7 & 0,785 \\
\hline \multirow{2}{*}{ Governança em rede } & \multirow[b]{2}{*}{0,77} & V8 & 0,872 \\
\hline & & V9 & 0,868 \\
\hline \multirow{6}{*}{$\begin{array}{l}\text { Benefícios da ação } \\
\text { em rede }\end{array}$} & \multirow{6}{*}{0,82} & V10 & 0,716 \\
\hline & & V11 & 0,746 \\
\hline & & V12 & 0,705 \\
\hline & & V13 & 0,686 \\
\hline & & V14 & 0,667 \\
\hline & & V15 & 0,641 \\
\hline \multirow{3}{*}{ Poder local } & \multirow{3}{*}{0,71} & V16 & 0,802 \\
\hline & & V17 & 0,832 \\
\hline & & V18 & 0,724 \\
\hline
\end{tabular}

Nota: $\alpha=$ Coeficiente Alfa de Cronbach.

Fonte: Elaborada pelos autores. 
A Tabela 2 reporta índices de confiabilidade de coerência interna significativos ( $\alpha$ do fator) e cargas fatoriais acima de 0,60 . Atesta-se ainda que os cinco construtos apresentaram KMO entre 0,542 e 0,760 (portanto, $\mathrm{KMO} \geq 0,500$ ).

As comunalidades indicaram um razoável poder explicativo do modelo: a variável menos explicativa, com 6I\% de explicação por meio dos fatores extraídos em conjunto do fator cooperação, foi a $\mathrm{V}_{3}$. Os autovalores apontaram para uma explicação conjunta dos cinco fatores de 50,45\%. Nisso, destaca-se a "cooperação" com maior poder de explicação, de $29,55 \%$.

A análise fatorial retornou com cinco construtos, nomeados: cooperação (COOP), confiança (CONF), governança em rede (GOV'), benefícios da ação em rede (BENEF) e poder local (PLOC), respectivamente, compostos de 4, 3, 2, 6 e 3 afirmações - portanto, total de I8 (ante as 52 iniciais) capazes de explicar 50\% da variação dos dados. Observa-se que, ante o modelo inicial, a análise fatorial dividiu a governança em duas: o poder local e a remanescente, no caso, a atuação do Sindvel. Excetuando-se esta particularidade, houve boa concordância entre o agrupamento da análise fatorial e os blocos de afirmações de partida, decorrente do modelo.

\subsection{APLICAÇÃO DA ANÁLISE POLINOMIAL}

As novas variáveis (representando os construtos) foram computadas usando como ponderação os escores fatoriais das variáveis (afirmações) originais em cada construto.

Daí, tais variáveis foram conduzidas para a análise de modelos polinomiais por meio de regressão múltipla a $5 \%$ de probabilidade (critério arbitrário, comum em amostras aleatórias e extrapolado para AAPL), a fim de compreender o comportamento (relação positiva/negativa) entre tais construtos e adequar o modelo. Para a determinação do grau do polinômio, foi realizada a análise de variância dos modelos de regressão polinomial por meio do estudo da significância estatística do modelo (com o senão de a AAPL não ser aleatória). Para o tratamento dos dados, utilizou-se o software XLSTAT.

O modelo de regressão polinomial de k-ésimo grau pode ser representado da seguinte forma (Gujarati, 2006):

$$
\mathrm{Y}=\beta_{\circ}+\beta_{\mathrm{I}} \mathrm{X}_{\mathrm{i}}+\beta_{2} \mathrm{X}_{\mathrm{i}}^{2}+\ldots+\beta_{\mathrm{K}} \mathrm{X}_{\mathrm{i}}^{\mathrm{k}}+\mathrm{u}_{\mathrm{i}}
$$

em que:

$\mathrm{Y}=$ variável dependente;

$\beta_{\circ}=$ intercepto; 
$\beta_{\mathrm{K}}=$ parâmetros do modelo $(\mathrm{k}=\mathrm{I}, 2,3 \ldots)$;

$\mathrm{X}_{\mathrm{i}}=$ variáveis do modelo $(\mathrm{i}=\mathrm{I}, 2,3 \ldots)$;

$\mathrm{K}$ = grau do polinômio;

$\mathrm{u}_{\mathrm{i}}=$ resíduo do modelo.

Na Figura 2, apresenta-se um novo modelo, aperfeiçoado do modelo original em função da indicação da análise fatorial. Na Figura I, a governança foi dividida em dois construtos: PLOC (atuação do poder local) e GOV' (atuação do Sindvel). Observa-se que existem outras possibilidades de relação, agora, por exemplo, entre PLOC e GOV', que foram desconsideradas no estudo pela sua não relevância teórica.

\section{FIGURA 2}

\section{MODELO DE ANÁLISE POLINOMIAL APLICADO}

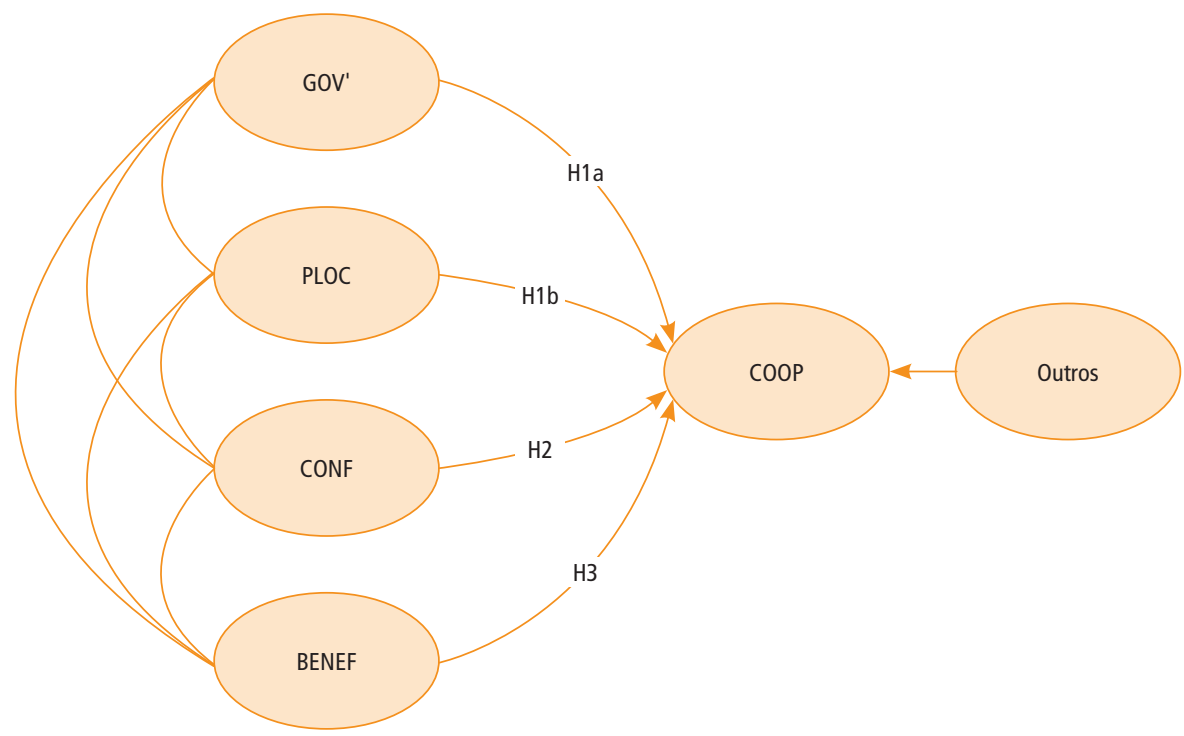

Variáveis BENEF = benefícios; $\mathrm{CONF}=$ confiança; $\mathrm{PLOC}=$ atuação do poder local; GOV'= atuação do Sindvel; COOP = cooperação; HıA, HıB, H2 E H3 = relações incorporadas ao modelo.

Fonte: Elaborada pelos autores.

Antes da apresentação dos resultados do tratamento estatístico, considera-se interessante oferecer sua contextualização, descrevendo mais amiúde o APL objeto da análise. 


\section{ANÁLISE DOS RESULTADOS}

Obedecendo aos procedimentos apresentados na subseção 4.4 e alimentando o software estatístico escolhido com as variáveis obtidas da análise fatorial, obteve-se a Equação I.

$$
\begin{aligned}
& \mathrm{Y}_{\mathrm{COOP}}=-0,04+0,4 \mathrm{GOV}^{\prime}+0,2 \mathrm{BENEF}+0, \mathrm{IPLOC}+0, \mathrm{ICONF}+0,03 \mathrm{GOV}^{\prime 2}+ \\
& 0, \mathrm{OIBENEF}^{2}+0, \mathrm{IPLOC}^{2}-0, \mathrm{ICONF}^{2}
\end{aligned}
$$

A Equação I, em que $Y_{\mathrm{Coop}}=\mathrm{f}$ (GOV', BENEF, PLOC, CONF), com os coeficientes de suas variáveis dotados de níveis de significância entre o,०० e ০,05 (limite tomado como aceitável), atingiu um coeficiente de determinação $R^{2}=0,59$, ou seja, as variáveis independentes se ajustaram ao modelo do construto cooperação em $59 \%$. O software empregado retornou com as seguintes estatísticas da bondade de ajuste, para as 82 observações: grau de liberdade (GL) de 52, soma dos quadrados do erro (SQE) de I34,03I, erro quadrático médio (EQM) de 2,062 e raiz quadrada do erro médio (RQEM) de I,436.

Os pesos (coeficientes) indicam que a propensão à cooperação aumenta quanto maior é (em ordem) a percepção positiva do trabalho do Sindvel (GOV') e da atuação do poder local (PLOC), cabendo à percepção dos benefícios auferidos, por se estar no APL, um papel secundário - com os dados corroborando as expectativas iniciais. Contudo, a Equação I traz um ponto intrigante: por ela, uma elevação na percepção de confiança reduziria a propensão a cooperar no âmbito do APL.

Admitindo a adequação dos procedimentos apresentados e a inexistência de alguma outra variável interveniente (oculta, no caso), seria aceitável apontar alguns pontos decorrentes da Equação I. O primeiro deles é a importância percebida sobre a atuação do Sindvel, seguido, em menor escala, pela atuação do poder local. Quanto mais bem-visto o Sindvel e, em menor escala, o poder local - ainda mais se ambas as avaliações forem positivas - maior foi a propensão a cooperar encontrada entre as empresas da AAPL. Isso poderia decorrer de fatores como:

- O Sindvel é o ente responsável pela integração e realização de ações conjuntas entre as empresas (cursos, palestras, treinamentos, assistência jurídica e promoção de eventos e missões nacionais e internacionais).

- O papel da prefeitura na facilitação de espaços para as empresas (criação e manutenção de distritos industriais) e sua atuação direta no apoio às empresas, por meio da IME e do CME (ações do Prointec).

- A atuação combinada do Sindvel e da prefeitura, em ações para captar recursos externos a serem canalizados para as empresas incubadas e do condomínio, 
bem como na caracterização aglutinadora do APL como "Vale da Eletrônica" (remetendo ao Vale do Silício, na Califórnia), interessante para atrair novos negócios.

Os benefícios listados no questionário foram relativos à troca de informação (de mercado, inclusive preços praticados pelos concorrentes e parceiros) e compartilhamento de recursos tecnológicos e comerciais (canais de distribuição). Uma percepção de maiores oportunidades de ganho nessas áreas se relacionou positivamente, mas fracamente, com maior propensão à cooperação (e variável naqueles que se dizem mais confiantes nas relações do APL, daí não seria razoável dizer que a percepção de benefícios aumenta a confiança relacional, no contexto do arranjo e no momento histórico atual).

O construto confiança derivou das respostas dos entrevistados às afirmações: I. posso confiar nas empresas com quais mantemos relações porque elas são transparentes e verdadeiras em seus propósitos; 2. confio nas empresas com as quais me relaciono porque conheço pessoalmente os seus dirigentes; e 3. posso confiar no comportamento ético e moral das empresas com as quais mantenho relacionamentos. A maior parte dos respondentes foi neutra (20\%) ou favorável (70\%) a essas afirmações, portanto a confiança está presente entre as empresas da AAPL, pois as indicações negativas foram inferiores a 10\% do total, mas, infelizmente, não há padrões de comparação, sendo somente possível obtê-los a partir da aplicação das mesmas perguntas em outros APL. Mesmo assim, parece razoável supor que a maioria das empresas confia nos outros membros do APL, quer por proximidade (conhecimento pessoal), quer porque as relações são transparentes e/ou pela crença no comportamento ético dos parceiros.

O construto cooperação derivou das respostas às afirmações: I. as relações de cooperação existentes entre as empresas têm contribuído para a ampliação da vantagem competitiva em relação aos concorrentes locais; 2. a cooperação entre empresas traz benefícios mútuos que dificilmente seriam alcançados sem a referida relação; 3. a contratação conjunta de serviços de consultorias especializadas tem sido considerada por nossa empresa como uma fonte de inovação relevante; 4. o conhecimento transferido por outras empresas tem contribuído de forma significativa para que nossa empresa obtenha vantagens competitivas no mercado - esta última listada originalmente como benefício e reposicionada pela análise fatorial. As respostas tiveram perfil semelhante ao daquelas apresentadas pelo construto confiança, com um pequeno aumento de opiniões neutras (de $20 \%$ para $30 \%$ ), com redução em igual extensão nas opiniões favoráveis. Os dirigentes das empresas reconhecem os benefícios do esforço cooperativo na criação e extração de valor de competências e na redução de custo (no caso, de consultorias). 
Seria razoável considerar que, à medida que um projeto é concebido, a empresa é constituída, incubada (quando já se espera um plano de negócios), depois "graduada" e passa a crescer; ela passa a ser demandada e a demandar cada vez mais formalização das relações em contratos, incluindo os de trabalho, os comerciais e aqueles celebrados com o poder público, até mesmo por imperativo legal dentro do horizonte burocrático do ordenamento nacional. Portanto, quando mais avançada se encontrar a consolidação do APL, maior será a propensão de as relações receberem intermediação por contratos, ainda mais se o poder público se fizer em evidência.

Adicional e tipicamente, a atuação no setor de tecnologia envolve inovações tecnológicas que trazem consigo considerações na órbita do direito de propriedade, mesmo de patente, que precisam ser observadas e resolvidas, o que envolve novamente a tradução de acordos em contratos formais.

Admitindo que o APL de Santa Rita já se encontra amadurecido, contando inclusive com empresas de portes médio e grande, considerando a interveniência decisiva do poder público e apontando a vocação tecnológica do arranjo, seria também plausível aceitar que os contratos são elementos presentes intermediando as relações no Vale da Eletrônica. Isso não dispensa a confiança. Ela continuaria a exercer um papel significativo, permitindo reduzir as salvaguardas dos contratos, o que reduz os custos das transações e, assim, facilita ajustes competitivos na cadeia de valor, favorecendo a especialização e a exploração das competências de cada firma, que confia, encontra parceiros, estabelece parcerias, formaliza-as e volta-se para o seu nicho. Essa proposição difere daquela de Williams (2005), para quem a formalização das relações poderia, em determinadas circunstâncias, impactar de forma negativa a cooperação (quando as definições formais de direitos e obrigações seriam contrárias ou substitutivas da confiança e da cooperação entre as organizações). A cooperação continuaria a acontecer, mesmo que formalizada e não dispensando o concurso da confiança. Adotando o viés da racionalidade utilitarista e elementos da economia dos custos de transação (Coase, I937; Williamson, I996), seria concebível apontar que a intensidade e a frequência das relações interfirmas no Vale da Eletrônica restringem o comportamento oportunista, valorizam a reputação e favorecem as relações interfirmas, ainda mais quando se observa a atuação de mais um elemento de governança: o Sindvel, que cria oportunidades para a consolidação do modelo. Disfuncionalidades, como descumprimento de contratos (formalizados ou informais), não passariam despercebidas nesse universo, mesmo porque estão circunscritas a uma área geográfica e com várias iniciativas em comum (feiras e missões) que favorecem os contatos e a circulação de informações.

No objeto em estudo, a confiança foi relegada a segundo plano, não porque ela esteja ausente, pelo contrário, por já estar instituída, é desconsiderada. 
Admita-se o oposto: se proliferasse o caráter oportunista e a perda de reputação fosse elemento desprezível, como explicar a intensidade das relações entre firmas em um sistema geograficamente restrito, no qual não há barreiras à troca de informações?

\section{CONSIDERAÇÕES FINAIS}

O APL de Santa Rita de Sapucaí demonstrou constituir um interessante objeto de pesquisa na medida em que foi encontrado dispondo dos elementos característicos dessa forma de rede, tal como preconizado por Porter (I998), Dyer e Singh, (1998), Lastres et al. (2003), como fator geográfico, atuação setorial (no caso, produto de base tecnológica), interdependência de empresas em relações de competição e de colaboração, interveniência de um conjunto de entidades provedoras de infraestrutura (prefeitura) e de serviços educacionais (ETE, FAI, Inatel), atuação de sindicato industrial (Sindvel) e do poder público na governança do sistema e geração de benefícios decorrentes do arranjo e apropriados pelas firmas. Ademais, seu estado de maturação e a produção tecnológica são outros atrativos consideráveis.

Outros trabalhos já intentaram entender a cooperação em ambientes de rede, tal como proposto aqui. Este é apenas mais um passo no entendimento de um fenômeno complexo, contemporâneo e dialético (cooperar e competir; rival e parceiro). Estudar a cooperação ambientada ao APL do Vale da Eletrônica rendeu alguns frutos.

O primeiro foi a comprovação da necessidade de trazer à coleta e à análise de dados a contextualização social e histórica, bem como reconhecer que as ações organizacionais são produzidas por pessoas que representam a organização. Tal como defendido por Ritter e Gemunden (2003) e Pesämaa e Hair (2008), quem confia e age são as pessoas operando em nome de suas organizações. Portanto, as entrevistas e o questionário respondido pelos dirigentes teriam tido endereço certo. E evitou-se a armadilha da análise puramente estatística, sem significado real, combatida por Hair et al. (2005), que colocaria em risco qualquer pretensão de validade do trabalho.

O segundo avanço adveio do trabalho estatístico. O modelo inicial foi sendo aprimorado ao longo da pesquisa, e aquele final, no atual estágio de vida do APL, teria de reservar maior espaço ainda para os elementos de governança e representar a linha cooperação-confiança $\left(\mathrm{H}_{5}\right)$ de forma descontínua: para um dado status de confiança institucionalizada, mais confiança pode não render mais cooperação, tal como encontrado por Williams (2005), ainda que por motivo diverso. 
Quanto às outras relações hipotéticas, é admissível afirmar que o teste a que elas foram submetidas falhou em refutá-las; portanto, elas permanecem, em especial aquelas emanadas da governança (Hı e H2), quer para confiança ou cooperação, bem como a ligação $\mathrm{H}_{4}$ entre benefícios e cooperação. Já a relação $\mathrm{H}_{3}$ entre benefícios e confiança restou inconclusa.

O APL de Santa Rita exemplificaria bem a importância de dois elementos institucionais: a governança (no caso, Sindvel e poder público local) e a interveniência de entidades educacionais que, além de assegurarem a qualificação da mão de obra, assumiram a tarefa de incubar empresas. Não parece inapropriado afirmar que o APL deve a sua criação e, mesmo, o seu desenvolvimento à atuação desses entes, conjuminada com a ação de pessoas visionárias, que ocuparam cargos diretivos nessas entidades, e também, obviamente, aos empresários, que assumiram os riscos.

Concluindo, é admissível assumir que os empresários estejam cônscios dos benefícios de serem tidos como integrantes do Vale de Eletrônica. Além de gozarem da proximidade geográfica, a indicação de um endereço em Santa Rita do Sapucaí pode ser entendida com outro diferencial, até mesmo para financiamento, como evidenciado com edital público específico para esse APL.

Como qualquer outra pesquisa, esta investigação sofreu com limitações. Entre outras, está o corte transversal dos dados do questionário: enquanto se admite a importância da dinâmica histórica, apresenta-se uma análise pontual. Assim sendo, o questionário deve ser reaplicado ao final de um período, cinco anos, quando será interessante observar as alterações das percepções dos empresários ao longo do tempo.

\section{COOPERATION IN THE CLUSTER OF SANTA RITA DO SAPUCAÍ}

\section{ABSTRACT}

In this paper we present the main results of a research that investigated the explanatory constructs of cooperation among the firms belonging to the Local Production Arrangement (LPA) located in Santa Rita do Sapucaí City, Minas Gerais State. Firstly, some aspects about the genesis, development and contemporary configuration of that arrangement are pointed out. Subsequently, we propose a theoretical and methodological framework that worked as a reference to provide the explanations of the relationships between the constructs of cooperation, trust and benefits, among others. Two multivariate techniques were applied to 
test and validate this proposal: the factor analysis and the polynomial regression. The research results showed correlations that suggest the positive perceptions of managers regarding the governance of the production arrangement, as well as the benefits from cooperation. In the managers' perception, the benefits generate individual and collective advantages for the firms surveyed. Finally, the results contradict some formulations of the theoretical-methodological framework used to explain the relationships of trust built up among the firms operating in the same territory. The results also suggest that the LPA in Santa Rita could be a good example of the relevance of two institutional elements: governance (in this case, the Union of the Electrical and Electronic Equipment Industry of Vale da Eletrônica - SINDIVEL - and the local government), and the mediation of educational entities which provide the qualification of the labor force and play the role of business incubators as well. It seems appropriate to attribute the LPA setting up and even its development to the role played by these entities, combined with the actions of the visionary people who were in charge of their management. Like any other research, this study has its limitations. Among others, is the cross-section of the data setting. While the study admits the relevance of taking into account the historical dynamic, it presents a punctual analysis.

\section{KEYWORDS}

Cooperation. Trust. Local cluster. Governance. Santa Rita do Sapucaí.

\section{COOPERACIÓN EN APL DE SANTA RITA DO SAPUCAÍ}

\section{RESUMEN}

En este artículo se presentan los principales resultados de una investigación acerca de los constructos explicativos de las relaciones de cooperación entre empresas que integran el arreglo productivo local (APL), ubicado en la ciudad de Santa Rita do Sapucaí, Minas Gerais. Inicialmente, se recuperaron algunos aspectos de la génesis, desarrollo y configuración actual de ese acuerdo. Posteriormente, fue elaborada una propuesta teórica y metodológica utilizada como referencia para explicar las relaciones entre los constructos de cooperación, confianza y beneficios, entre otros. Para testar y validar esa propuesta se aplicaron dos técnicas de análisis multivariados, el análisis factorial y la regresión polinomial. El análisis de los resultados indicó la existencia de correlaciones que sugieren la percepción positiva de los dirigentes con relación a la gobernanza del arreglo productivo y los beneficios de la cooperación. Los dirigentes perciben las ventajas individuales 
y colectivas de los beneficios para las empresas participantes de la investigación. Finalmente, los resultados contradicen algunas de las formulaciones de la propuesta teórico-metodológica utilizada para explicar las relaciones de confianza construidas entre las empresas que operan en el mismo territorio. Los resultados sugieren también que el APL Santa Rita sería un buen ejemplo de la importancia de dos elementos institucionales: la gobernanza (en este caso, el Sindicato de la Industria de Aparatos Eléctricos y Electrónicos del Vale da Eletrônica - Sindvel - y el gobierno local) y de la intervención de las entidades educativas que no solamente proporcionan la calificación de la fuerza de trabajo, sino también desempeñan el papel de incubadoras de negocios. Parece apropiado atribuir la creación del APL y aun su desarrollo al papel desempeñado por las entidades educativas, juntamente con las acciones de las personas visionarias que estuvieron a cargo de su gestión. Así como cualquier otra investigación, este estudio tiene sus limitaciones. Entre otras, está el corte transversal de los datos mientras se admite la importancia de la dinámica histórica, se presenta un análisis puntual.

\section{PALABRAS CLAVE}

Cooperación. Confianza. Arreglo productivo local. Gobernanza. Santa Rita do Sapucaí.

\section{REFERÊNCIAS}

Amaral, J., Filho (20II). Sistemas e arranjos produtivos locais. Planejamento e Políticas Públicas, 36, I7I-2I2.

Araújo, U. P. (20II). Dinâmica em redes aplicada à pesquisa de café no Brasil. Organizações Rurais \& Agroindustriais, 13(2), 257-269.

Baiardi, A. (2008). Competição e competição/cooperação. Organizações \& Sociedade, 15(45), 46-6o. Baiardi, A., \& Laniado, R. N. (2000). Entre a competição e a cooperação. Organizações \& Sociedade, 7(I9), I7-I9.

Balestrin, A., \& Vargas, L. M. (2004). A dimensão estratégica das redes horizontais de PMEs: teorizações e evidências. Revista de Administração Contemporânea, 8(Número Especial), 203-227.

Baptista, R., \& Swann, P. (I998). Do firms in clusters innovate more? Research Policy, 27(5), 525-540. Bercovitz, J., Jap, S. D., \& Nickerson, J. A. (2006). The antecedents and performance implications of cooperative exchange norms. Organization Science, 17(6), 724-744.

Bijlsma-Frankema, K. (2004). Dilemmas of managerial control in post-acquisition processes. Journal of Managerial Psychology, 19(3), 252-268.

Botelho, M. dos R., Carrijo, M. de, \& Kamasaki, G. Y. (2007). Inovações, pequenas empresas e interações de ensino/pesquisa em arranjos produtivos locais de setores de tecnologia avançada. Revista Brasileira de Inovação, 6(2), 33I-37I. 
Brusco, S. (I990). The idea of the industrial districts: its genesis. In F. Pyke, G. Becattini \& W. Sengenberg (Eds.). Industrial districts and inter-firm cooperation in Italy (pp. IO-I9). Geneva: International Institute for Labour Studies.

Carvalho, A. M. A. (2009). Novos enfoques no campo da ciência da informação: uma discussão sobre a aplicabilidade do conceito de regime de informação em arranjos produtivos locais. Perspectivas em Ciência da Informação, 14(Número Especial), 213-227.

Cassiolato, J. E., \& Szapiro, M. (2003). Uma caracterização de arranjos produtivos locais de micro e pequenas empresas. In H. M. M. Lastres, J. E. Cassiolato \& M. L. Maciel (Orgs.). Pequena empresa: cooperação e desenvolvimento local (pp. 35-50). Rio de Janeiro: Relume Dumará.

Churchill, G. (I994). Marketing research: methodological foundations. New York: The Dryden Press. Ciccone, A., \& Cingano, F. (2003). Skills and clusters. In J. Bröcker, D. Dohse \& R. Oltwedel (Orgs.). Innovation clusters and interregional competition (pp. 218-237). Kiel: Springer.

Coase, R. (I937). The nature of the firm. Economica, 4, 386-405.

Dyer, J. H., \& Singh, H. (1998).The relational view: cooperative strategy and sources of interorganizational competitive advantage. Academy of Management Review, 23(4), 660-679.

Edelenbos, J., \& Klijn, E. H. (2007).Trust in complex decision-making networks; a theoretical and empirical exploration. Administration and Society, 39(I), 25-50.

Eriksson, P.-E., \& Pesämaa, O. (2007). Modelling procurement effects on cooperation. Construction Management and Economics, 25(8), 893-90I.

Federação das Indústrias do Estado de Minas Gerais (2004). Diagnóstico do arranjo produtivo da indústria eletrônica de Santa Rita do Sapucaí. Belo Horizonte: Fiemg.

Federação das Indústrias do Estado de Minas Gerais (2007). Diagnóstico do arranjo produtivo da indústria do Vale da Eletrônica. Belo Horizonte: Fiemg.

Grandori, A., \& Soda, G. (I995). Inter-firm network. Organization Studies, 16(2), I83-2I4.

Guadagnoli, E., \& Velicer, W. (I988). Relation of sample size to the stability of component patterns. Phychology Bulletin, 103(2), 265-275.

Gujarati, D. (2006). Econometria básica (4a ed.). Rio de Janeiro: Campus.

Gulati, R., \& Sytch, M. (2008). Does familiarity breed trust?: revisiting the antecedents of trust. Managerial and Decision Economics, 29(Special Issue), I65-I90.

Hair, J. F., Junior, Babin, B., Money, A. H., \& Samouel, P. (2005). Fundamentos de pesquisa em administração. Porto Alegre: Bookman.

Hanna, V., \& Walsh, K. (2008). Cooperation among small manufacturing firms. International Small Business Journal, 26(3), 299-321.

Humphrey, J., \& Schmitz, H. (2002). How does insertion in global value chains affect upgrading in industrial clusters? Regional Studies, 36(9), I0I7-IO27.

Inkpen, A. C., \& Curral, S. (2004). The coevolution of trust, control, and learning in joint ventures. Organization Science, 15(5), 586-599.

Lane, C. (I998). Introduction: theories and issues in the study of trust. In C. Lane \& R. Bachmann (Orgs.). Trust within and between organizations (pp. I-30). Oxford: Oxford University.

Lastres, H. M. M., \& Cassiolato, J. E. (2003). Glossário de arranjos e sistemas produtivos e inovativos locais. Rio de Janeiro: UFRJ-IE.

Lastres, H. M. M., Cassiolato, J. E., \& Maciel, M. L. (2003). Pequena empresa: cooperação e desenvolvimento local. Rio de Janeiro: Relume Dumará. 
Lewicki, R. J., \& Bunker, B. B. (I996). Developing and maintaining trust in work relationships. In R. M. Kramer \& T. R. Tyler (Eds.). Trust in organizations (pp. 438-458). Thousand Oaks: Sage. Lopes, B., Muÿlder, C. F. de, \& Judice, V. M. M. (20II). Influência competitiva e o caso de um Arranjo Produtivo Local de eletrônica brasileiro. Revista Gestão e Planejamento, 12(2), 2I3-23I.

Lundin, M. (2007). Explaining cooperation: how resource interdependence, goal congruence, and trust affect joint actions in policy implementation. Journal of Public Administration Research and Theory, 17(4), 65I-672.

MacCallun, R. R., Widaman, K. F., Zhang, S., \& Hong, S. (I999). Sample size in factor analysis. Psychological Methods, 4(I), 84-99.

Malhotra, N. K. (200I). Pesquisa de marketing: uma orientação aplicada (3a ed.). Porto Alegre: Bookman. Marconi, M. A., \& Lakatos, E. M. (2003). Fundamentos de metodologia científica (5a ed.). São Paulo: Atlas. Maroco, J. (2007). Análise estatística com a utilização do SPSS. Lisboa: Edições Silabo.

Marshall, A. (1966). Principles of economics: an introductory (8th ed.). London: Macmillan.

Martins, R. S., \& Souza, O. V., Filho (2013). A efetividade da colaboração entre organizações do arranjo produtivo local (APL): experiências de processos logísticos nas indústrias do Vale de Eletrônica de Minas Gerais - Brasil. Redes - Revista de Desenvolvimento Regional, 18(2), 8-37.

Matos, S. T., \& Quelhas, O. L. G. (2007). Organizações humanamente sustentáveis: estudo de caso em organizações de base tecnológica. Organização \& Estratégia, 3(3), 277-30I.

Matos, S. T., \& Quelhas, O. L. G. (2008). Organizações humanamente sustentáveis: estudo de caso em organizações de base tecnológica, um foco na gestão de pessoas. RGSA - Revista de Gestão Social e Ambiental, 2(2), I-I2.

McEvily, B., Perrone, V., \& Zaheer, A. (2003). Introduction to the special issue on trust in an organizational context. Organization Science, 14(I), I-4.

Medlin, C. (2006). Self and collective interest in business relationships. Journal of Business Research, 59, 858-865.

Oliveira, T. M. V. de. (200Ia). Escalas de mensuração de atitudes: Thurstone, Osgood, Stapel, Likert, Guttman, Alpert. Administração Online. Prática - Pesquisa - Ensino, 2(2). Recuperado em Io outubro, 20II, de http://www.fecap.br/adm_online/art22/tania.htm.

Oliveira, T. M. V. de. (200Ib). Amostragem não probabilística: adequação de situações para uso e limitações de amostras por conveniência, julgamento e quotas. Administração Online. Prática Pesquisa - Ensino, 2(3). Recuperado em Io outubro, 20II, de http://www.fecap.br/adm_online/ art23/tania2.htm.

Parrilli, M. D. (2007). SME cluster development: a dynamic view of survival clusters in developing countries. London: Palgrave-Macmillan.

Pesämaa, O., \& Hair, J. F. (2007). More than friendship is required: an empirical test of cooperative firm strategies. Management Decision, 45(3), 602-615.

Pesämaa, O., \& Hair, J. F. (2008). Cooperative strategies for improving the tourism industry in remote geographic regions. Scandinavian Journal of Hospitality and Tourism, 8(I), 48-6I.

Prado, O., \& Costa, A. B. (20I3). Uma pequena cidade e sua vocação para a alta tecnologia. In M. V. Gomes, M. A. Alves \& R. J. Fernandes (Orgs.). Políticas públicas de fomento ao empreendedorismo e às micro e pequenas empresas (pp. I57-I66). São Paulo: PGPC.

Popper, K. (I994). Conjecturas e refutações. Brasília: UnB. 
Porter, M. E. (1998). Clusters and the new economics of competition. Harvard Business Review, 76(6), 77-90.

Porter, M. E. (I999). Arranjos e competição: novas agendas para empresas, governo e instituições. In M. E. Porter. Competição: estratégias competitivas essenciais (pp. 209-303). Rio de Janeiro: Campus. Porter, M. E. (2000). Location, competition, and economic development: local clusters in a global economy. Economic Development Quarterly, 14(I), I3-34.

Pouder, R., \& John, C. S. (I996). Hot spots and blind spots: geographical clusters of firms and innovation. Academy Management Review, 21(4), II92-I225.

Ritter, T., \& Gemunden, H. G. (2003). Interorganizational relationship and networks: an overview. Journal of Business Research, 56, 691-697.

Santos, I. C., \& Paula, R. M. de. (20I2). A especialização tecnológica local como indutora do empreendedorismo e do desenvolvimento regional: o caso do Vale da Eletrônica brasileiro. Gestão $\&$ Regionalidade, 28(82), 65-82.

Schmitter, P., \& Streeck, W. (I985). Comunità, mercato, stato e associazioni? Il possibile contributivo dei governi privati all'ordine sociale. Stato e Mercato, I3, 47-86.

Serviço Brasileiro de Apoio às Micro e Pequenas Empresas (2003). Termo de referência para atuação do SEBRAE em arranjos produtivos locais. Recuperado em I8 junho, 20IO, de http://www.biblioteca.sebrae. com.br/bte/bte.nsf/DowContador?OpenAgent\&unid=50533C7F21014E5Fo3256FB7005C40BB.

Stallivieri, F., Guimarães, G., \& Souza, G. J. de. (2008). Processos de aprendizagem e cooperação: uma análise exploratória da influência sobre o desempenho inovativo. Anais do Encontro Nacional de Economia, Salvador, BA, Brasil, 36 .

Suzigan, W., Garcia, R., \& Furtado, J. (2007). Estruturas de governança em arranjos ou sistemas locais de produção. Gestão \& Produção, 14(2), 425-439.

Sydow, J., \& Windeler, A. (2003). Knowledge, trust, and control. International Studies of Management \& Organization, 33(2), 69-99.

Tavares, H. M. (20II). Estratégias de desenvolvimento regional: da grande indústria ao arranjo produtivo local. Revista Brasileira de Gestão e Desenvolvimento Regional, 7(I), 50-68.

Vasconcelos, F. C., Goldszmidt, R. G. B., \& Ferreira, C. M. (2005). Arranjos produtivos. GV Executivo, 4(3), I7-2I.

Verschoore, J. R. S., \& Balestrin, A. (2008). Fatores relevantes para o estabelecimento de redes de cooperação entre empresas do Rio Grande do Sul. Revista de Administração Contemporânea, 12(4), 1043-1069.

Vilela, C. M., Perreira, F., Neto, \& Adriano, J. D. (2008). Diagnóstico da aplicação dos fundamentos gerenciais de projetos nas empresas do APL de Eletroeletrônica de Santa Rita do Sapucaí. Revista Científica da FAI, 8(I), 70-76.

Williams, T. (2005). Cooperation by design. Journal of Business Research, 58(2), 223-23I.

Williamson, O. E. (I996). The mechanisms of governance. New York: Oxford University Press. 